\title{
Integrated UPLC-HRMS, Chemometric Tools, and Metabolomic Analysis of Forage Palm (Opuntia spp. and Nopalea spp.) to Define Biomarkers Associated with Non-Susceptibility to Carmine Cochineal (Dactylopius opuntiae)
}

\author{
Thiago Kelvin B. Matos, ${ }^{\oplus \#, a, b}$ Jhonyson A. C. Guedes, ${ }^{\oplus \sharp a, b}$ Elenilson G. Alves Filho, ${ }^{\circ}$ \\ Licia R. Luz, ${ }^{a, b}$ Gisele Simone Lopes, ${ }^{\circledR b}$ Ronaldo F. do Nascimento, ${ }^{b}$ João A. de Sousa, ${ }^{a}$ \\ Kirley M. Canuto, ${ }^{a}$ Edy S. de Brito, ${ }^{a}$ Nivia S. Dias-Pini ${ }^{a}$ and Guilherme J. Zocolo*,a \\ ${ }^{a}$ Empresa Brasileira de Pesquisa Agropecuária, Embrapa Agroindústria Tropical, \\ Rua Dra. Sara Mesquita, 2270, Pici, 60020-181 Fortaleza-CE, Brazil \\ ${ }^{b}$ Departamento de Química Analítica e Físico-Química, Universidade Federal do Ceará, \\ Av. Humberto Monte, s/n, Pici, 60455-760 Fortaleza-CE, Brazil \\ 'Departamento de Engenharia de Alimentos, Universidade Federal do Ceará, \\ Campus do Pici, Bloco 858, 60440-900 Fortaleza-CE, Brazil
}

\begin{abstract}
Metabolomics, together with analytical methods and chemometric tools, point to new paths for selecting species that are resistant to pests and diseases. In this work, the forage palm species' metabolomic profile was investigated, and the relation between the chemical composition and resistance to Dactylopius opuntiae (carmine cochineal). The study was performed in cladodes of different non-susceptible cultivars (Nopalea cochenillifera (L.) Salm-Dyck, Opuntia stricta (Haw.), Nopalea cochenillifera and susceptible cultivar (Opuntia ficus-indica (L.) Mill.)). Metabolic profile showed 28 metabolites detected in the four species. From these total, 18 metabolites were annotated using UPLC-QTOF-MS ${ }^{\mathrm{E}}$ (ultra-performance liquid chromatography coupled with an electrospray ionization quadrupole time-of-flight mass spectrometry operating in $\mathrm{MS}^{\mathrm{E}}$ mode). By comparing the chemical profiles of non-susceptible and susceptible species through the application of chemometric tools, it was possible to obtain biomarkers (quercetin-3-O-2',6'-dirhamnosylglucoside, quercetin rhamnosyl dihexoside, and isorhamnetin-3-sophoroside-7-rhamnoside) that may be associated with resistance to carmine cochineal. Metabolomics based on UPLC-QTOF-MS ${ }^{\mathrm{E}}$ and chemometric allowed to establish the biomarkers knowledge of the resistance present in forage palm species. These results contribute to developing the initial understanding of flavonoids' role in the defense mechanisms of cactaceans and can be useful for application in breeding programs; it can increase the chances of success in creating new varieties of plants not susceptible to carmine cochineal.
\end{abstract}

Keywords: Cactaceae, Dactylopius opuntiae, UPLC-QTOF-MS ${ }^{\mathrm{E}}$, chemometrics

\section{Introduction}

Some forage palm, among which Opuntia spp. and Nopalea spp. (Cactaceae family) are well adapted to the arid and semi-arid conditions; also, it has a wide variety of germplasm, being cultivated in all the continents, except in Antarctica. ${ }^{1-8}$ In Brazil, mainly in semi-arid regions, it is considered one of the primary sources of forage for dairy cattle during the dry period of the year due to the high palatability. In addition to animal and human food, it can be used as an ornamental plant to prevent soil degradation

*e-mail: guilherme.zocolo@embrapa.br

"These authors contributed equally to this work. and control desertification, energy production, medicinal function, and a cosmetic composition. ${ }^{3-5,8}$

Opuntia spp. and Nopalea's chemical composition varies with cultivar, stage of development, fertilization, plant population, and cladode order. However, they have low content of dry matter (5-20\%), the main constituent being water $(80-95 \%)$, followed by small amounts of carbohydrates (3-7\%), fibers (1-2\%), and proteins (0.5-1\%). ${ }^{9-11}$ Besides these nutrients, it also presents a significant amount of minerals rich in $\mathrm{Ca}^{2+}, \mathrm{Mg}^{2+}, \mathrm{Na}^{+}$, $\mathrm{K}^{+}, \mathrm{Fe}^{2+}, 11,12$ besides phenolic compounds and flavonoids, carotenoid, and vitamins. ${ }^{9-11,13-16}$

Among the problematic pests that attack the crop, the carmine cochineal (Dactylopius opuntiae) (Hemiptera: 
Dactylopiidae) is a significant threat to forage palm because of its potential to render plants unviable economically. This insect produces carminic acid to protect itself from predators, which can be used in the cosmetic, food, pharmaceutical, and textile industries. ${ }^{17,18}$ In Brazil, D. opuntiae is considered a key crop pest. It weakens the plant and can cause chlorosis (yellowing) of rackets and the cladodes' fall. ${ }^{19}$ In more severe attacks, when no control measure is adopted, plant death may occur, and destruction of the whole plantation..$^{18}$ Its control has been mainly carried out using insecticides. However, due to its high cost and possible environmental implications, it is difficult, mainly due to small rural producers' socio-economic conditions.

Thus, the best alternative for cultivating forage palm in regions attacked by this insect is planting resistant cultivars with resistance to carmine cochineal. Host plant resistance is an essential tool for integrated pest management (IPM). It is low-cost, more durable, and reduces the risk of developing resistant pests to registered active ingredients. ${ }^{20}$ Resistance to $D$. opuntiae has already been observed in cultivars Nopalea cochonellifera (L.) Salm-Dyck, Opuntia stricta (Haw.) and N. cochonellifera, varieties cultivated in Brazil. On the other hand, the giant forage palm cultivar (Opuntia ficus-indica (L.) Mill.), also produced, although on a smaller scale, is susceptible to infestation of D. opuntiae. . $^{21,22}$

Several secondary metabolites are involved in the insect-plant interaction; identifying such compounds may help obtain cactus pear varieties resistant to pests through traditional breeding techniques and modern biotechnology. Thus, a quick way to distinguish the various metabolites of the same plant is to conduct a study of these plants' metabolomics. The variation in metabolites is observed mainly by analyzing the total changes in chromatographic patterns. ${ }^{23-26}$ The association of chromatography data with chemometric tools to treat multivariate data and pattern recognition, considering many chemical analysis results, helps to interpret and evaluate data effectively. Thus, the various metabolic data obtained using this approach allow the comparison between samples based on multivariate statistical methods, such as principal component analysis $(\mathrm{PCA})^{27}$ and orthogonal projections to latent structures discriminant analysis (OPLS-DA). ${ }^{28}$

This work aims to evaluate the use of ultra-performance liquid chromatography coupled with an electrospray ionization quadrupole time-of-flight mass spectrometry operating in $\mathrm{MS}^{\mathrm{E}}$ mode (UPLC-QTOF-MS ${ }^{\mathrm{E}}$, E represents collision energy) to find biomarkers that can distinguish different species of Cactaceae, in addition to identifying secondary metabolites that confer resistance to D. opuntiae.

\section{Experimental}

\section{Plant material}

Samples of the species of Nopalea cochenillifera (L.) Salm-Dyck (IPA Sertânia), Opuntia stricta (Haw.) ("palma orelha de elefante mexicana"), and Nopalea cochenillifera ("palma doce") have been cultivated in the city of Trairi (CE, Brazil $\left(3^{\circ} 16^{\prime} 40.0^{\prime \prime} \mathrm{S}\right.$ $\left.39^{\circ} 16^{\prime} 08.0^{\prime \prime} \mathrm{W}\right)$ ). Sample collection was performed, so that, the respective species were studied in sample pool systems; in this study, a mixture of five clones per species $(\mathrm{n}=5)$ was performed. The species Opuntia ficus-indica (L.) Mill. ("palma gigante", control), susceptible to attack by Dactylopius opuntiae (Hemiptera: Dactylopiidae), were provided by Empresa de Pesquisa Agropecuária do Rio Grande do Norte (EMPARN, Brazil).

\section{Chemicals}

The reagents used for this work's development were purchased from LiChrosolv ${ }^{\circledR}$ of the Sigma-Aldrich Chemical Company (St. Louis, MO, USA). The ultrapure water was obtained by the Milli- ${ }^{\circledR}$ water-purification system from Millipore (Billerica, MA, USA).

\section{Sample preparation}

Each plant material (200 g), was initially subjected to a bath with liquid $\mathrm{N}_{2}$ for inactivation of the metabolism. Then, it was cut into cubes of $1 \mathrm{~cm} \times 1 \mathrm{~cm}$, lyophilized for four days, and ground in a knife mill. $10 \mathrm{~g}$ of the samples were extracted in biological triplicate in the accelerated solvent extraction (ASE) system from Thermo Scientific ${ }^{\mathrm{TM}}$ Dionex $^{\text {TM }}$ ASE $^{\text {TM }} 350$ (Waltham, MA USA). They were previously homogenized in $5 \mathrm{~g}$ of diatomaceous earth, added to $66.0 \mathrm{~mL}$ cells, and extracted with 70:30 ethanol/ water $(\mathrm{v} / \mathrm{v})$ at the temperature of $80^{\circ} \mathrm{C}$, in 3 cycles of extraction with $10 \mathrm{~min}$ of duration. The resulting extracts were evaporated entirely under reduced pressure and lyophilized. The material was stored at $-80^{\circ} \mathrm{C}$.

The second step in the extraction process was carried out by weighing $15 \mathrm{mg}$ of each extract solubilized in $3.0 \mathrm{~mL}$ of a 90:10 (v/v) methanol/water solution, sonicated for $10 \mathrm{~min}$, filtered on PTFE membrane $0.45 \mu \mathrm{m}$. The resulting extract was subjected to solid-phase extraction using C18-E (55 $\mu \mathrm{m}, 70 \mu \mathrm{m})$ cartridges of $100.0 \mathrm{mg} / 3.0 \mathrm{~mL}$ for each sample. The cartridges were activated with $10.0 \mathrm{~mL}$ of methanol and conditioned with $10.0 \mathrm{~mL}$ of Milli-Q ${ }^{\circledR} \mathrm{H}_{2} \mathrm{O}$. A volume of $3 \mathrm{~mL}$ of the samples was percolated in the cartridges. Cartridge cleaning was performed with $1.0 \mathrm{~mL}$ of Milli-Q $\mathrm{H}_{2} \mathrm{O}$. The 
sample was eluted with $3 \mathrm{~mL}$ of $90: 10$ methanol/water (v/v) solution. The eluate was collected and filtered on a $0.22 \mu \mathrm{m}$ PTFE (polytetrafluoroethylene) membrane. Subsequently, the volume of each eluate of interest was measured in a $5 \mathrm{~mL}$ volumetric flask with 90:10 (v/v) methanol/water solution, so that, all samples had the same concentration $\left(1.5 \mathrm{mg} \mathrm{mL}^{-1}\right)$. After all the procedures were performed, the samples were injected into the system UPLC-QTOF-MS ${ }^{\mathrm{E}}$.

\section{Chromatographic conditions}

The chromatographic study was carried out in Acquity UPLC (Waters), coupled to a quadrupole time-of-flight (QTOF, Waters Corporation, Milford, MA, USA). The analyzes were performed on a column $\mathrm{C} 18$ Waters Acquity UPLC BEH $(150 \mathrm{~mm} \times 2.1 \mathrm{~mm}, 1.7 \mu \mathrm{m}), 40{ }^{\circ} \mathrm{C}$, mobile phase: water with $0.1 \%$ formic acid (A) and acetonitrile with $0.1 \%$ formic acid (B), gradient varying $0-15 \mathrm{~min}$ (2-95\%) B, (15.1-17) $\min (100 \%)$ of B, and (17.1-19.1) min (2\%) B, $0.4 \mathrm{~mL} \mathrm{~min}^{-1}$ flow and $5 \mu \mathrm{L}$ injection volume.

\section{Mass spectrometry conditions}

The electrospray ionization in negative mode $\left(\mathrm{ESI}^{-}\right)$ was acquired in the range of 110-1180 Da, fixed source temperature at $120^{\circ} \mathrm{C}$, desolvation temperature $350{ }^{\circ} \mathrm{C}$, the desalting gas flow of $500 \mathrm{~L} \mathrm{~h}^{-1}, 0.5 \mathrm{~V}$ extraction cone, $2.6 \mathrm{kV}$ capillary voltage. At the low scan, the cone voltage was $35 \mathrm{~V}$, collision energy of $5 \mathrm{eV}$ (trap). The $\mathrm{ESI}^{+}$mode was purchased in the range of 110-1180 $\mathrm{Da}$, fixed source temperature at $120^{\circ} \mathrm{C}$, desolvation temperature $350{ }^{\circ} \mathrm{C}$, the desalting gas flow of $500 \mathrm{~L} \mathrm{~h}^{-1}, 0.5 \mathrm{~V}$ extraction cone, voltage capillary of $3.2 \mathrm{kV}$. Leucine enkephalin was used as a lock mass. The MS mode used Xevo G2-XS QTOF. The spectrometer operated with $\mathrm{MS}^{\mathrm{E}}$ centroid programming using a tension ramp from 20 to $40 \mathrm{~V}$. The instrument was controlled by the MassLynx 4.1 program (Waters Corporation, Milford, MA, USA).

The samples were injected in triplicates in positive and negative ionization modes. A set of chromatograms and mass spectra were obtained for each of the four samples from the forage palm.

\section{Identification of chemical compounds}

The molecular formulas and the $\mathrm{m} / \mathrm{z}$ values obtained from high-resolution spectra observed at the highest intensity chromatographic peaks were considered for the chemical identification. From each formula, the relative error in ppm was determined. Only molecular formulas with values below $10 \mathrm{ppm}$ of error were considered for further MS/MS studies. The molecular structural proposals were carried out through MS/MS data, through the establishment of rational fragmentation patterns. ${ }^{29-33}$

A comparison of all chromatographic peaks was performed using a retention time tolerance deviation $\pm 0.05 \mathrm{~min}$ and an exact mass tolerance of $\pm 0.05 \mathrm{Da}$. For unidentified peaks, all possible molecular formulas were extracted (elements $\mathrm{C}, \mathrm{H}, \mathrm{N}, \mathrm{O}$, the tolerance of $10 \mathrm{ppm}$ at least 2 carbon atoms) with the elemental composition tool of MassLynx.

\section{Multivariate statistical analysis}

\section{Heat map analysis}

The peaks area of the leading organic compounds identified in forage palm species were imported into GENE-E program $^{34}$ for pattern recognition using the hierarchical clustering analysis (HCA) model. The Euclidean distance method was used to measure the proximity between the samples (columns), and the results are visualized as a 2-D dendrogram (heat map): deeper red color represents the higher relative intensity; deeper blue color the lower relative intensity; and the intermediary intensity in white color.

\section{Unsupervised evaluation by principal component analysis}

The chromatograms were converted to American standard code for information interchange (ASCII) files to construct the numerical matrix. To reduce the original data dimensionality and observe composition trends under a $95 \%$ confidence level, the matrix was exported for chemometric evaluation by PCA using the software Matlab ${ }^{\mathrm{TM}}$ with the PLS Toolbox package. ${ }^{35}$ Algorithms for baseline correction and normalization were applied over the variables (chromatograms), and the sample's data were mean-centered. The singular value decomposition (SVD) algorithm was used to decompose the matrix.

Supervised evaluation by orthogonal partial least squares discriminant analysis

The chromatograms were preprocessed using the software MarkerLynx XS 4.1 software program. ${ }^{36}$ For data collection, the method's parameters were defined at a retention time interval of 0.50-8.0 min, a mass range of 110-1200 Da, a mass tolerance of $0.05 \mathrm{Da}$, and a noise elimination level set at 5 . A generated list was made to identify the peaks detected using the retention time $\left(\mathrm{t}_{\mathrm{R}}\right)$ and mass data $(\mathrm{m} / \mathrm{z})$. An arbitrary identification was assigned to each one of these pairs $\left(t_{R}\right.$ and $m / z$ ) based on the elution order of the UPLC system. The ions' identification was based on the $\mathrm{t}_{\mathrm{R}}$ and $m / z$ values compared with previously published data regarding the genus, the family, and species (chemotaxonomic approach) with the aid of databases ChemSpider ${ }^{37}$ and PubChem. ${ }^{38}$ The 
ion intensities for each detected peak were normalized against the sum of the sample's peak intensities using MarkerLynx. ${ }^{36}$ The ions of different samples were considered the same when combined with their $t_{R}$ and $m / z$ values. Therefore, the orthogonal projections to OPLS-DA were developed to corroborate the marker compounds for susceptible and non-susceptible species to attack by $D$. opuntiae. ${ }^{39}$

\section{Results and Discussion}

\section{Metabolite annotation by UPLC-QTOF-MSE}

The samples were analyzed UPLC-QTOF-MS ${ }^{\mathrm{E}}$ in $\mathrm{ESI}^{+}$and $\mathrm{ESI}^{-}$ionization modes. In general, the two ionization modes are mainly used to corroborate the compounds present in the extracts, aiding in identifying the molecules through positive and negative ionization. However, it was possible to observe that some peaks do not appear in the two ionization modes.

Figure 1 illustrates a comparison among the chromatograms plotted in the same intensity from each forage palm species. The peaks in chromatograms have a spectrum of masses to be analyzed. Therefore, the MS and MS/MS spectra were acquired, and the fragmentation study of the molecules in the extracts was performed. Table 1 describes the chemical compounds annotated in the respective extracts from four forage palm species. Also, the fragmentation of higher intensity and references that corroborate these metabolites identifications are presented. It is essential to highlight that 28 compounds were detected in the species profiling established through the $\mathrm{MS}^{\mathrm{E}}$ spectra; through the dereplication, 18 compounds were annotated according to data previously published to the chemotaxonomy.

Peak $1(2.13 \mathrm{~min})$ showed a precursor ion $[\mathrm{M}+\mathrm{H}]^{+}$ at $m / z \quad 166.0869\left(\mathrm{C}_{9} \mathrm{H}_{11} \mathrm{NO}_{2}\right)$, which was assigned to a compound described in the literature, was annotated as the amino acid phenylalanine. Wrona et al. ${ }^{40}$ describe the fragment ion at $m / z 120.0813$, a specific fragment of phenylalanine, and the loss of the $\mathrm{CHO}_{2}$ group. The same was detected in the positive injection mode.

Peak 2 (2.28 min), the ion was observed $[\mathrm{M}-\mathrm{H}]^{-}$at $\mathrm{m} / \mathrm{z}$ $255.0508\left(\mathrm{C}_{11} \mathrm{H}_{12} \mathrm{O}_{7}\right)$, being identified as piscidic acid. This molecule has been previously reported in Opuntia. ${ }^{41}$ The ion $\mathrm{m} / z 193.0504$ was generated by the successive losses of $\mathrm{H}_{2} \mathrm{O}$ and $\mathrm{CO}_{2}$. The presence of piscidic acid in the samples was also confirmed by the analysis in the positive ionization mode, with fragments similar to those in the negative mode, adding the ion $m / z$ 144.0447.

Compound 3 (2.50 $\mathrm{min}$ ) is an unidentified molecule, $[\mathrm{M}-\mathrm{H}]^{-}$at $m / z 447.1132\left(\mathrm{C}_{18} \mathrm{H}_{24} \mathrm{O}_{13}\right)$, and not cited in any reference consulted. However, this molecule has fragmentations characteristic of the isorhamnetin group, $m / z$ 315.0822. The fragment ion at $m / z 152.0092$ may be the group directly attached to isorhamnetin, so that, the compound may be a derivative of isorhamnetin. The compound was not detected in $\mathrm{ESI}^{+}$.

Compound 4 (2.75 $\mathrm{min}$ ) was annotated as the amino acid tryptophan, $[\mathrm{M}+\mathrm{H}]^{+}$at $m / z 205.0976\left(\mathrm{C}_{11} \mathrm{H}_{12} \mathrm{~N}_{2} \mathrm{O}_{2}\right)$. Fragments originating in the MS/MS are cataloged by Wrona et al. ${ }^{40}$ as specific tryptophan fragments. Compound 5 (2.98 $\mathrm{min}$ ) is also an unidentified molecule, $[\mathrm{M}-\mathrm{H}]^{-}$at $m / z 959.3202\left(\mathrm{C}_{46} \mathrm{H}_{56} \mathrm{O}_{22}\right)$; however, it was detected by Semedo. ${ }^{41}$ The molecule did not respond in positive ionization mode, and its fragmentation shows that it is probably a derivative of kaempferol due to fragment $m / z$ 285.0390. The fragment ion at $m / z 813.2678$ is due to the loss of a rhamnoside, which has a mass of $146 \mathrm{Da}^{41}$

Compound 6 (3.21 min) was annotated as eucomic acid. The fragment that gave rise to the signal $\mathrm{m} / \mathrm{z}, 179.0379$ shows the loss of an acetic acid group of the eucomic acid molecule, a loss of $60 \mathrm{Da}$ about precursor ion $[\mathrm{M}-\mathrm{H}]^{-}$at $m / z 239.0562$

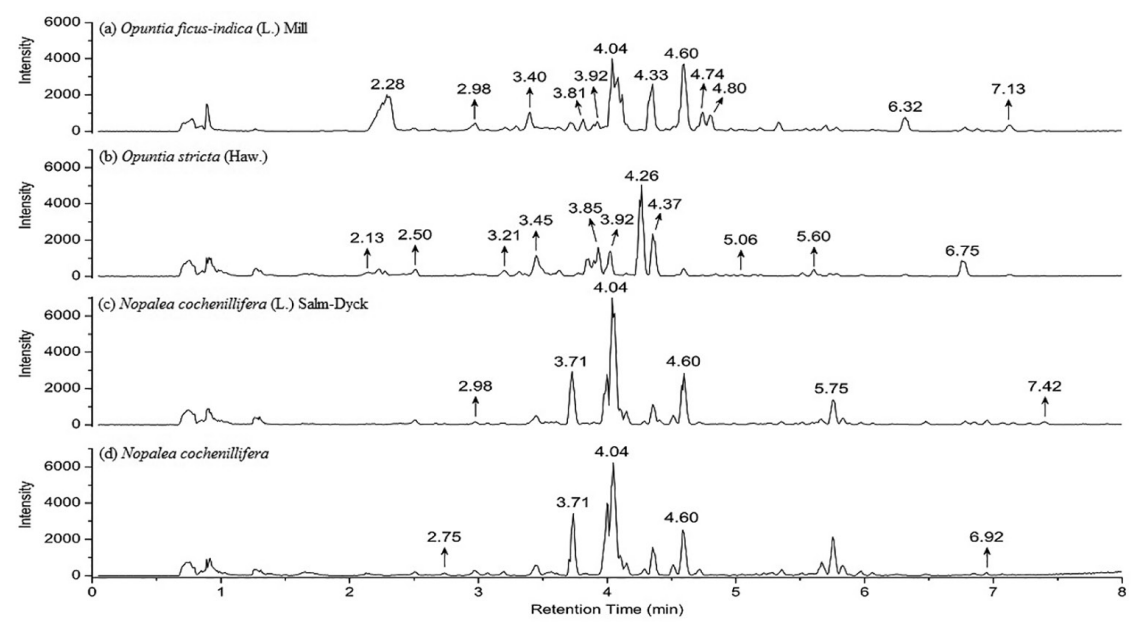

Figure 1. Chromatograms of samples of forage palm species (negative mode): (a) Opuntia ficus-indica (L.) Mill., (b) Opuntia stricta (Haw.), (c) Nopalea cochenillifera (L.) Salm-Dyck, and (d) Nopalea cochenillifera. 
$\left(\mathrm{C}_{11} \mathrm{H}_{12} \mathrm{O}_{6}\right)$. The molecule does not respond to the positive ionization mode and has already been reported in Opuntia. ${ }^{9,42}$

Compounds $\mathbf{7}$ (3.40 min), $\mathbf{1 3}$ (3.92 $\mathrm{min}$ ), $\mathbf{1 7}$ (4.37 min), 21 (5.06 min), 22 (5.60 min), 25 (6.75 min), 26 (6.92 min), and 28 (7.42 $\mathrm{min}$ ), Table 1, were not identified and had no reference in the literature consulted.

Compounds 8 (3.45 min), 11 (3.81 $\mathrm{min})$, and $\mathbf{1 5}$ $(4.26 \mathrm{~min})$ are isomers that have the precursor ion $[\mathrm{M}-\mathrm{H}]^{-}$ at $m / z, 785.2136\left(\mathrm{C}_{34} \mathrm{H}_{42} \mathrm{O}_{21}\right)$ and similar products ions. Thus, compounds $\mathbf{8}$ and $\mathbf{1 1}$ were annotated as isorhamnetin3-O-rutinoside-7-O-glucoside and isorhamnetin-
3-O-rudnoside-4'- $O$-glucoside. The fragmentation pattern showed the loss of hexose forming the ion at $\mathrm{m} / \mathrm{z} 623.1558$ [M- $\mathrm{H}-162]^{-}$, also was observed the ion at $\mathrm{m} / \mathrm{z} 639.1594$ $[\mathrm{M}-\mathrm{H}-146]^{-}$from the loss of deoxyhexose. The ion $\mathrm{m} / \mathrm{z} 315.0447[\mathrm{M}-\mathrm{H}-162-146-162]^{-}$is ascribable to the aglycone mass, resulting from the loss of two hexose units and one unit of deoxyhexose. ${ }^{43,44}$ Compound $\mathbf{1 5}$ was annotated as isorhamnetin-3-sophoroside-7-rhamnoside due to fragment ion at $m / z 459.1037[\mathrm{M}-\mathrm{H}-146-180]^{-}$. The loss of 180 Da corresponding to the loss of the terminal glucosyl of a sophorosyl moiety. ${ }^{45}$

Table 1. Metabolite annotation in samples in positive and negative ionization modes

\begin{tabular}{|c|c|c|c|c|c|c|c|c|c|c|c|c|}
\hline \multirow[b]{2}{*}{ Peak } & \multirow[b]{2}{*}{$\begin{array}{l}\mathrm{t}_{\mathrm{R}} / \\
\min \end{array}$} & \multicolumn{4}{|c|}{ Negative ion mode } & \multicolumn{4}{|c|}{ Positive ion mode } & \multirow{2}{*}{$\begin{array}{l}\text { Molecular } \\
\text { formula }\end{array}$} & \multirow[b]{2}{*}{ Metabolite annotation } & \multirow[b]{2}{*}{ Reference } \\
\hline & & $\begin{array}{l}{[\mathrm{M}-\mathrm{H}]^{-}} \\
\text {observed }\end{array}$ & $\begin{array}{l}{[\mathrm{M}-\mathrm{H}]^{-}} \\
\text {calculated }\end{array}$ & MS/MS & $\begin{array}{c}\text { Error / } \\
\mathrm{ppm}\end{array}$ & $\begin{array}{l}{[\mathrm{M}+\mathrm{H}]^{+}} \\
\text {observed }\end{array}$ & $\begin{array}{l}{[\mathrm{M}+\mathrm{H}]^{+}} \\
\text {calculated }\end{array}$ & MS/MS & $\begin{array}{c}\text { Error / } \\
\mathrm{ppm}\end{array}$ & & & \\
\hline 1 & 2.13 & - & - & - & - & 166.0869 & 166.0868 & 120.0813 & 0.6 & $\mathrm{C}_{9} \mathrm{H}_{11} \mathrm{NO}_{2}$ & phenylalanine & 40 \\
\hline 2 & 2.28 & 255.0508 & 255.0505 & $\begin{array}{c}193.0504 \\
165.0513\end{array}$ & 1.2 & 257.0655 & 257.0661 & $\begin{array}{l}193.0510 \\
144.0447\end{array}$ & -2.3 & $\mathrm{C}_{11} \mathrm{H}_{12} \mathrm{O}_{7}$ & piscidic acid & 41 \\
\hline 3 & 2.50 & 447.1132 & 447.1139 & $\begin{array}{c}315.0822 \\
152.0092\end{array}$ & -1.6 & - & - & - & - & $\mathrm{C}_{18} \mathrm{H}_{24} \mathrm{O}_{13}$ & ni & - \\
\hline 4 & 2.75 & - & - & - & - & 205.0976 & 205.0977 & $\begin{array}{c}188.0723 \\
146.0608 \\
143.0740\end{array}$ & -0.5 & $\mathrm{C}_{11} \mathrm{H}_{12} \mathrm{~N}_{2} \mathrm{O}_{2}$ & tryptophan & 40 \\
\hline 5 & 2.98 & 959.3202 & 959.3185 & $\begin{array}{l}813.2678 \\
285.0390\end{array}$ & 1.8 & - & - & - & - & $\mathrm{C}_{46} \mathrm{H}_{56} \mathrm{O}_{22}$ & ni & - \\
\hline 6 & 3.21 & 239.0562 & 239.0556 & $\begin{array}{l}179.0379 \\
149.0596\end{array}$ & 2.5 & - & - & - & - & $\mathrm{C}_{11} \mathrm{H}_{12} \mathrm{O}_{6}$ & eucomic acid & 46 \\
\hline 7 & 3.40 & 533.1458 & 533.1448 & $\begin{array}{l}405.2111 \\
259.0593\end{array}$ & 1.9 & - & - & - & - & $\mathrm{C}_{29} \mathrm{H}_{26} \mathrm{O}_{10}$ & ni & - \\
\hline 8 & 3.45 & 785.2136 & 785.2140 & $\begin{array}{l}623.1558 \\
315.0509\end{array}$ & -0.5 & - & - & - & - & $\mathrm{C}_{34} \mathrm{H}_{42} \mathrm{O}_{21}$ & $\begin{array}{l}\text { isorhamnetin- } \\
\text { 3- } O \text {-rutinoside-7- } O \text {-glucoside or } \\
\text { isorhamnetin-3- } O \text {-rutinoside- } \\
\text { 4'- } O \text {-glucoside }\end{array}$ & 43,44 \\
\hline 9 & 3.45 & - & - & - & - & 479.1200 & 479.1190 & 317.0628 & 2.1 & $\mathrm{C}_{22} \mathrm{H}_{22} \mathrm{O}_{12}$ & isorhamnetin hexoside I & 42 \\
\hline 10 & 3.71 & 755.2035 & 755.2035 & 301.0315 & 0.0 & 757.2194 & 757.2191 & 303.0504 & 0.4 & $\mathrm{C}_{33} \mathrm{H}_{40} \mathrm{O}_{20}$ & $\begin{array}{l}\text { quercetin-3-O-2",6"- } \\
\text { dirhamnosylglucoside }\end{array}$ & 47 \\
\hline 11 & 3.81 & 785.2146 & 785.2140 & $\begin{array}{l}639.1594 \\
623.1570 \\
315.0482\end{array}$ & 0.8 & - & - & - & - & $\mathrm{C}_{34} \mathrm{H}_{42} \mathrm{O}_{21}$ & $\begin{array}{c}\text { isorhamnetin- } \\
\text { 3- } O \text {-rutinoside-7- } O \text {-glucoside or } \\
\text { isorhamnetin-3-O-rutinoside- } \\
\text { 4'- } O \text {-glucoside }\end{array}$ & 43,44 \\
\hline 12 & 3.85 & 771.1977 & 771.1984 & $\begin{array}{l}609.1472 ; \\
301.0302\end{array}$ & -0.9 & - & - & - & - & $\mathrm{C}_{33} \mathrm{H}_{40} \mathrm{O}_{21}$ & quercetin rhamnosyl dihexoside & 48 \\
\hline 13 & 3.92 & 931.2621 & 931.2626 & $\begin{array}{l}417.1549 \\
315.0480\end{array}$ & -0.5 & - & - & - & - & $\mathrm{C}_{29} \mathrm{H}_{56} \mathrm{O}_{33}$ & ni & - \\
\hline 14 & 4.04 & 769.2183 & 769.2191 & 315.0480 & -1.0 & 771.2399 & 771.2348 & $\begin{array}{l}757.2249 \\
317.0620\end{array}$ & 6.6 & $\mathrm{C}_{34} \mathrm{H}_{42} \mathrm{O}_{20}$ & $\begin{array}{l}\text { isorhamnetin-glucosyl-di- } \\
\text { rhamnoside }\end{array}$ & 49 \\
\hline 15 & 4.26 & 785.2111 & 785.2140 & $\begin{array}{l}623.1735 ; \\
459.1037 \\
315.0447\end{array}$ & 3.7 & & & & & $\mathrm{C}_{34} \mathrm{H}_{42} \mathrm{O}_{21}$ & $\begin{array}{l}\text { isorhamnetin-3-sophoroside- } \\
\text { 7-rhamnoside }\end{array}$ & 50 \\
\hline 16 & 4.33 & 609.1466 & 609.1456 & 315.0451 & 1.6 & - & - & - & - & $\mathrm{C}_{27} \mathrm{H}_{30} \mathrm{O}_{16}$ & isorhamnetin-pentosyl-glucoside & 49 \\
\hline 17 & 4.37 & - & - & - & - & 647.1675 & - & - & - & - & ni & - \\
\hline 18 & 4.60 & 623.1629 & 623.1612 & $\begin{array}{l}315.0414 \\
300.0242\end{array}$ & 2.7 & 625.1794 & 625.1769 & $\begin{array}{l}317.0620 \\
302.0424\end{array}$ & 4.0 & $\mathrm{C}_{28} \mathrm{H}_{32} \mathrm{O}_{16}$ & $\begin{array}{l}\text { isorhamnetin-3- } O \text {-rhamnosyl } \\
\text { hexoside }\end{array}$ & 48 \\
\hline 19 & 4.74 & 477.1017 & 477.1033 & $\begin{array}{l}315.0474 \\
299.0164\end{array}$ & -3.4 & 479.1227 & 479.1190 & $\begin{array}{l}317.0646 \\
287.0539\end{array}$ & 7.7 & $\mathrm{C}_{22} \mathrm{H}_{22} \mathrm{O}_{12}$ & isorhamnetin-3- $O$-hexoside I & 51 \\
\hline 20 & 4.80 & 477.1005 & 477.1033 & $\begin{array}{l}314.0411 \\
299.0217\end{array}$ & -5.9 & & & & & $\mathrm{C}_{22} \mathrm{H}_{22} \mathrm{O}_{12}$ & isorhamnetin-3-O-hexoside II & 51 \\
\hline 21 & 5.06 & - & - & - & - & 512.2746 & - & - & - & - & ni & - \\
\hline 22 & 5.60 & - & - & - & - & 526.2972 & - & - & - & - & ni & - \\
\hline 23 & 5.75 & 801.2231 & 801.2242 & 315.0482 & -1.4 & - & - & - & - & $\mathrm{C}_{38} \mathrm{H}_{42} \mathrm{O}_{19}$ & isorhamnetin-3-O-triglucoside & 52 \\
\hline 24 & 6.32 & 315.0513 & 315.0505 & $\begin{array}{l}300.0272 \\
271.0228\end{array}$ & 2.5 & 317.0663 & 317.0661 & $\begin{array}{l}302.0424 \\
274.0480\end{array}$ & 0.6 & $\mathrm{C}_{16} \mathrm{H}_{12} \mathrm{O}_{7}$ & isorhamnetin & 42,53 \\
\hline 25 & 6.75 & 603.2938 & - & - & - & 605.3230 & - & - & - & - & $\mathrm{ni}$ & - \\
\hline 26 & 6.92 & 533.2997 & - & - & - & - & - & - & - & - & ni & - \\
\hline 27 & 7.13 & 285.0387 & 285.0399 & $\begin{array}{l}255.0292 \\
227.0335\end{array}$ & -4.2 & 287.0540 & 287.0566 & $\begin{array}{l}257.0501 \\
229.0490\end{array}$ & -5.6 & $\mathrm{C}_{15} \mathrm{H}_{10} \mathrm{O}_{6}$ & kaempferol & 42,53 \\
\hline 28 & 7.42 & - & - & - & - & 573.2527 & - & - & - & - & ni & - \\
\hline
\end{tabular}

$\mathrm{t}_{\mathrm{R}}$ : retention time; MS: mass spectrometry; ni: not identified. 
Peak 9 (3.45 min) was annotated as isorhamnetin hexoside I, $[\mathrm{M}+\mathrm{H}]^{+}$at $\mathrm{m} / z 479.1200\left(\mathrm{C}_{22} \mathrm{H}_{22} \mathrm{O}_{12}\right)$. The fragment $m / z, 317.0628$ is due to the hexoside unit loss (162 Da), leaving the only isorhamnetin. The compound was not detected in a negative mode..$^{42}$

Compound 10 (3.71 min), was annotated as quercetin3-O-2",6"-dirhamnosylglucoside, was observed in both ionization modes, $[\mathrm{M}-\mathrm{H}]^{-}$at $\mathrm{m} / z 755.2035$ and $[\mathrm{M}+\mathrm{H}]^{+}$ at $m / z$ 757.2194 $\left(\mathrm{C}_{33} \mathrm{H}_{40} \mathrm{O}_{20}\right)$. The fragment ions were observed $\mathrm{m} / \mathrm{z} 301.0315$ and 303.0504, in negative and positive modes, respectively; the formation of these ions are attributed to the successive losses of two rhamnosyl units and a glucoside unit. ${ }^{47}$

Compound 12 (3.85 $\mathrm{min})$ was annotated as quercetinrhamnosyl-dihexoside, $[\mathrm{M}-\mathrm{H}]^{-}$at $\mathrm{m} / z$. 771.1977, which has characteristic fragmentation of quercetin derivatives, $\mathrm{m} / \mathrm{z} 609.1472[\mathrm{M}-\mathrm{H}-162]^{-}$, resulting from the loss of a hexose, besides, also the ion is observed $\mathrm{m} / z 301.0302$ $[\mathrm{M}-\mathrm{H}-162-146]^{-}$resulting from the successive losses of two units of hexose and one unit of rhamnoside. ${ }^{48}$

Compound 14 (4.04 min) was annotated as isorhamnetin glucosyl-di-rhamnoside, $[\mathrm{M}-\mathrm{H}]^{-}$at $m / z, 769.2183$ and $[\mathrm{M}+\mathrm{H}]^{+}$at $m / z, 771.2399\left(\mathrm{C}_{34} \mathrm{H}_{42} \mathrm{O}_{20}\right)$. The precursor ion $[\mathrm{M}-\mathrm{H}]^{-}$, originated the product fragment ion at $\mathrm{m} / \mathrm{z} 315.0480$ characteristic of isorhamnetin aglycone, revealing the loss of $454 \mathrm{Da}$ correspondent to two rhamnoside units $(2 \times 146 \mathrm{Da})$ and a hexoside unit $(162 \mathrm{Da}){ }^{49}$

Compound 16 (4.33 min) was annotated as isorhamnetin pentosyl-glucoside, [M- $]^{-}$at $m / z 609.1442\left(\mathrm{C}_{27} \mathrm{H}_{30} \mathrm{O}_{16}\right)$. The fragment ion is formed from the losses of a hexose (162 Da) and a pentosyl (132 Da), leaving the aglycone, $\mathrm{m} / z 315.0451[\mathrm{M}-\mathrm{H}-162-132]^{-}$. This compound was previously determined in Opuntia spp. ${ }^{49}$

Compound 18 (4.60 $\mathrm{min})$ was annotated as isorhamnetin3-O-rhamnosyl hexoside, $[\mathrm{M}-\mathrm{H}]^{-}$at $\mathrm{m} / \mathrm{z} 623.1629$ $\left(\mathrm{C}_{28} \mathrm{H}_{32} \mathrm{O}_{16}\right)$. The fragment $m / z, 300.0242$ is due to the loss of the two sugar units (162 Da of hexoside + 146 Da of the rhamnoside) and the isorhamnetin conversion to quercetin loss of a methyl group. ${ }^{48}$

Compounds 19 (4.74 $\mathrm{min})$ and $20(4.80 \mathrm{~min})$ showed ions $[\mathrm{M}-\mathrm{H}]^{-}$at $\mathrm{m} / \mathrm{z} 477.1017$ and 477.1005 $\left(\mathrm{C}_{22} \mathrm{H}_{22} \mathrm{O}_{12}\right)$, respectively. The compounds were annotated as isorhamnetin-3-O-hexoside isomers, both of which have been described by Brito et al. ${ }^{51}$ The characteristic fragment ion around 315.0474 $\mathrm{Da}$ indicates the presence of isorhamnetin.

Compound 23 (5.75 min) showed precursor ion $[\mathrm{M}-\mathrm{H}]^{-}$ at $m / z 801.2231\left(\mathrm{C}_{38} \mathrm{H}_{42} \mathrm{O}_{19}\right)$ was previously reported in the literature, ${ }^{52}$ as isorhamnetin-3-O-triglucoside. The characteristic ion fragment at $m / z 315.0482$ was caused by the loss of the three glycoses attached to the isorhamnetin molecule $(3 \times 162 \mathrm{Da})$. The same was not detected in positive mode.

Compound 27 (7.13 min), was annotated as kaempferol, $[\mathrm{M}-\mathrm{H}]^{-}$at $m / z 285.0387$ and $[\mathrm{M}+\mathrm{H}]^{+}$at $\mathrm{m} / z 287.0540$ $\left(\mathrm{C}_{15} \mathrm{H}_{10} \mathrm{O}_{6}\right)$. The ion products $\mathrm{m} / z 227.0335$ and $\mathrm{m} / z 255.0292$ are characteristic of kaempferol, according to literature. ${ }^{42,53}$

\section{Multivariate analyses}

Different chemometric approaches such as HCA, PCA, and OPLS-DA were performed from collected data to obtain an overview and understand the composition variability among the forage palm species. Initially, HCA's agglomerative method was applied, and all similarities among the forage palm species (biological triplicate) are shown in Figure 2 as a 2D dendrogram in heat map form. According to the columns, three separation tendencies may be visualized. $O$. stricta was the most different forage palms species from the others by the higher amounts of the compound at $2.13 \mathrm{~min}$ (phenylalanine), $3.21 \mathrm{~min}$ (eucomic acid), $3.45 \mathrm{~min}$ (isorhamnetin hexoside I), $3.85 \mathrm{~min}$ (quercetin rhamnosyl dihexoside), and $4.26 \mathrm{~min}$ (isorhamnetin-3-sophoroside7-rhamnoside). Besides, O. ficus-indica is the susceptible species separated from the others by the higher amounts of piscidic acid (2.28 min), isorhamnetin-3-O-rutinoside7-O-glucoside (3.81 min), isorhamnetin-pentosyl-glucoside (4.33 min), isorhamnetin-3-O-rhamnosyl hexoside

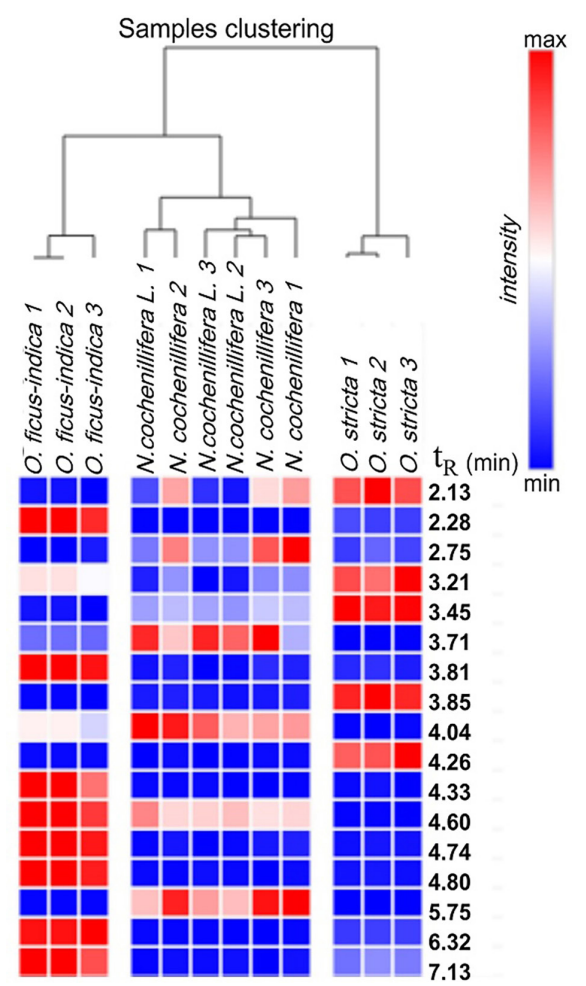

Figure 2. Dendrogram representing the chemical composition similarity relationship among the species of forage palm. 
(4.60 min), isorhamnetin-3- $O$-hexoside I (4.74 min), isorhamnetin-3- $O$-hexoside II (4.80 $\mathrm{min})$, isorhamnetin (6.32 $\mathrm{min}$ ), and kaempferol (7.13 $\mathrm{min})$.

Figure 3 illustrates the PCA results from the evaluation of different forage palms species by the scores (Figure 3a), influence plot (Figure 3b), and loadings (Figure 3c) with $95.99 \%$ of the total variance. The PC1 axis presented relevant information for forage palm separation according to the genus Opuntia and Nopalea. In general, both Nopalea species at positive scores showed higher amounts of the compounds quercetin3-O-2', 6'-dirhamnosylglucoside (10), isorhamnetinglucosyl-di rhamnoside (14), isorhamnetin-3-O-rhamnosyl hexoside (18), and isorhamnetin-3-O-triglucoside (23). On the other hand, both Opuntia species presented higher amounts of isorhamnetin-3-sophoroside-7-rhamnoside (15), mainly the forage palm species $O$. stricta (Haw). Also, the PC2 axis was essential to differentiate the Opuntia species by the higher amounts of quercetin3-O-2',6'-dirhamnosylglucoside (10), isorhamnetin3-sophoroside-7-rhamnoside (15), and isorhamnetin3-O-triglucoside (23) in $O$. stricta (Haw) at negative scores, as well as the higher amounts of piscidic acid (2), isorhamnetin-glucosyl-di-rhamnoside (14), isorhamnetinpentosyl-glucoside (16), isorhamnetin-3-O-rhamnosyl hexoside (18), isorhamnetin-3-O-hexoside I (19), isorhamnetin-3-O-hexoside II (20), isorhamnetin (24), and kaempferol (27) in O. ficus-indica (L.) at positive scores. The influence biplot, according to Hotelling $\mathrm{T}^{2} \times \mathrm{Q}$-residuals, clearly showed the absence of samples negatively influencing the modeling (outliers at both values above 1 , upper left quadrant).

To corroborate the biomarker compounds for discrimination of the susceptible (O. ficus-indica (L.) Mill.) and non-susceptible forage palm species (O. stricta (Haw.), N. cochenillifera (L.) Salm-Dyck, and Nopalea cochenillifera), OPLS-DA modeling associated with S-Plot analysis was applied separately for each binary classification as susceptible/non-susceptible species (Figure 4). Therefore, three classification analyses were performed, which showed a clear separation between the two groups (susceptible and non-susceptible) by the highlighted chromatogram peaks (described in Table 1) on S-Plot. To verify the quality of the resulting OPLS-DA model, two parameters were used: $\mathrm{Q}^{2}$ (predicted variance) and the predicted model of the variables and $R^{2} Y$ (variance explained), which is the degree of explanation that the model possesses under the data presented. The results of $\mathrm{R}^{2} \mathrm{Y}(99 \%)$ and $\mathrm{Q}^{2}(99 \%)$ indicating the good quality of the model.

The S-Plot is a scatter plot that illustrates the magnitude of each variable's correlation in the data set with the samples in the OPLS-DA, where each point represents an ion (pair $\mathrm{t}_{\mathrm{R}}-m / z$ ). Signals (peaks) with low magnitude $\left(\mathrm{P}_{1}\right)$ and low correlation $\left(\mathrm{P}_{\text {corr }}\right)$ are close to the noise level

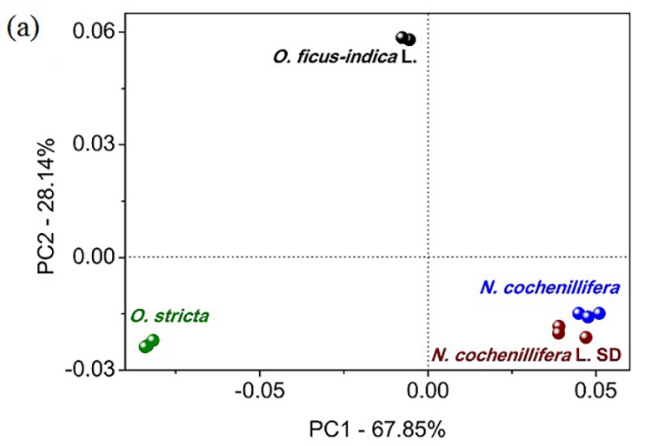

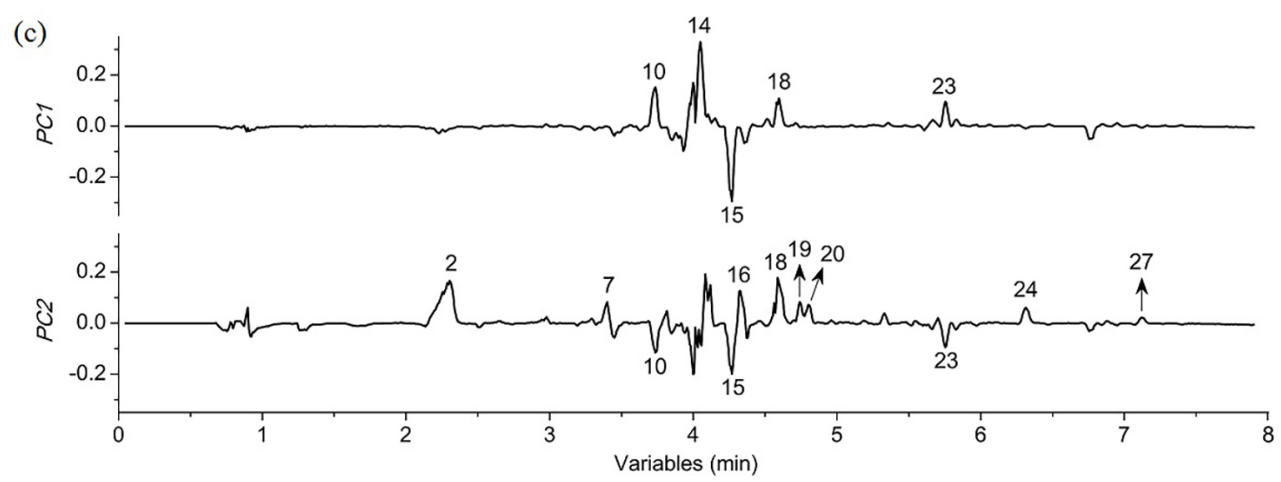

Figure 3. PCA results: (a) scores of the forage palm samples, (b) influence plot by Hotelling $\mathrm{T}^{2} \times \mathrm{Q}$ residuals with $95 \%$ confidence limit, (c) respective loadings plotted in lines form: Opuntia ficus-indica (L.) Mill. in black, Nopalea cochenillifera in blue, Opuntia stricta (Haw.) in green, and Nopalea cochenillifera (L.) Salm-Dyck in red. 

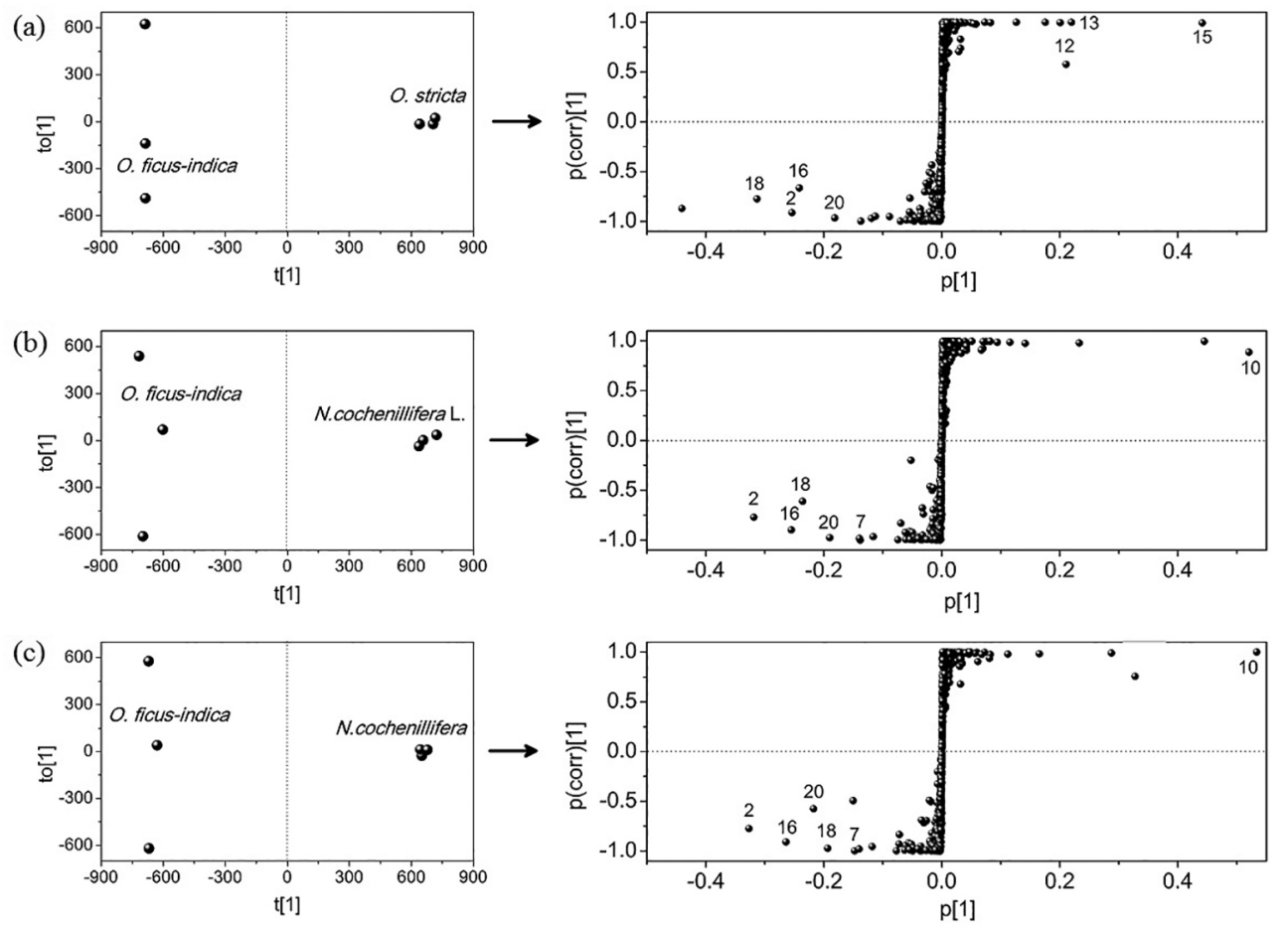

Figure 4. Relationship of the secondary metabolites with resistance to D. opuntiae by binary classification using OPLS-DA (left) and the S-Plot (right) with the peaks number: (a) Opuntia ficus-indica (L.) Mill. $\times$ Opuntia stricta (Haw.), (b) Opuntia ficus-indica (L.) Mill. $\times$ Nopalea cochenillifera (L.) Salm-Dyck, and (c) Opuntia ficus-indica (L.) Mill. × Nopalea cochenillifera.

if they are closer to zero. The ideal markers present high magnitude $\left(\mathrm{P}_{1}\right)$ and high correlation $\left(\mathrm{P}_{\text {corr }}\right)$, with the signals that appear farthest from zero..$^{54}$

In this context, it is possible to infer by S-Plots that the peaks 10,12, 13, and 15, (Table 1), respectively correspondent to the secondary metabolites quercetin3-O-2',6'-dirhamnosylglucoside, quercetin rhamnosyl dihexoside, not identified, isorhamnetin-glucosyldi-rhamnoside and isorhamnetin-3-sophoroside7-rhamnoside, which may be strongly associated with non-susceptible forage palm species explored in this work.

It was important to note that among the studied species, $N$. cochenillifera, $N$. cochenillifera (L.) Salm-Dyck, and $O$. stricta (Haw.) are resistant to carmine cochineal (Dactylopius opuntiae). On the other hand, the species O. ficus-indica (L.) Mill. is the only one susceptible. Therefore, these possible biomarkers associated with non-susceptible species may be correlated with resistance to cochineal carmine action in defense of the plant. These compounds are more prominent in species resistant to the pest (Figures 2 and 4). However, there may be other compounds associated with resistance, but they were not identified in the present study due to limitations in the techniques used.

Among the secondary metabolites, flavonoids are among the most common and widespread groups of defense compounds, which play an essential role in the host plant's resistance against herbivorous insects. ${ }^{55-58}$ Thus, the flavonoids identified in the present study may be associated with the resistance of forage palm species to carmine cochineal.

Many flavonoids can act as deterrents for phytophagous insects, even at relatively low concentrations, ${ }^{59,60}$ besides acting as digestibility reducers, repellents, and toxic to insects. ${ }^{61-64}$ In studies with larvae of Trichoplusia $n i$ and Anticarsia gemmatalis (fed with soy leaves Glycine max Merrill) demonstrated that the presence of flavonoids rutin and quercetin-3-glucosyl glucoside, in combination with genistein, acted synergistically by making it difficult to consume and accumulate food in the larvae. High concentrations of these compounds are present in soybean genotypes resistant to Lepidoptera-plague. Thus, flavonoids can be used in breeding programs as a source of resistance against defoliant insects, including the development of resistant cultivars expressing specific flavonoids. ${ }^{59,65}$

In maize plants, the most likely defense substances are flavonoids, the presence of $C$-glycosyl flavone, maysin (2"-O- $\alpha$-L-rhamnosyl-6-C-(6-deoxy-xylo-hexos-4-ulosyl) luteolin), provides resistance to Helicoverpa zea, and is generally more abundant in genotypes resistant to this pest. With high amounts of these compounds, transgenic maize showed more excellent resistance to corn earworms, which presented lower weight and higher mortality due to the compounds' deterrent effect. ${ }^{66}$ 
Other authors have also observed the negative effects of flavonoids on the performance of phytophagous insects. In an experiment performed with canola (Brassica napus L.), it was observed that phenolic compounds including isorhamnetin-3-sophoroside-7-glucoside and kaempferol3,7-diglucoside promoted the reduction of larval weight and the development time of larvae and pupae of Mamestra configurata (Walk.); thus acting as food detergent and prolonging the feeding time of this species-pest. ${ }^{67}$ This phenomenon was also observed, studying biological aspects of Helicoverpa armigera and Spodoptera frugiperda, fed with added rutin diets, observed an inhibitory effect on the feeding behavior of these species, providing prolongation and delay in development. ${ }^{68,69}$ For sucking insects, it was found that the cultivar of soybean, with a higher concentration of flavonoids, caused a higher mortality rate of Bemisia tabaci biotype B. Also, the rutin content increases during the development of the plant, coinciding with the reduction in the survival of the nymphs of B. tabaci. Thus, flavonoids are probably related to the defense of soy to chewing and sucking insects. The effects of naringenin and quercetin (two polyphenolic flavonoids) are recognized to play an essential role in defending the plant against other sucking insects. ${ }^{70}$ In the literature, some reports demonstrated the adverse effects of naringenin on the behavior of the Acyrthosiphon pisum. ${ }^{71}$

The results showed that further studies are needed to determine the mechanisms of action of these biomarkers, mostly flavonoids, found in Nopalea cochenillifera (L.) Salm-Dyck, Opuntia stricta (Haw.), and Nopalea cochenillifera. The study is the basis for implementing methods based on advanced phenotyping, using target analyzes to select pest-resistant materials, thus increasing the plant's defense power.

\section{Conclusions}

The present study compared the chemical profile of four forage palm species, in which the only one is susceptible to cochineal carmine and the other resistant ones. In total, 28 metabolites were detected in the forage palm species, of which 18 were annotated. The derivatives of isorhamnetin, quercetin, and kaempferol stand out as the forage palm's main components, presenting great variety and intensity in the samples.

PCA provided good separation of the four forage palm species, thus indicating a distinction between them. It was also possible to identify the compounds responsible for the difference between forage palm species. The OPLS-DA and S-Plot analyzes pointed out the biomarkers that are possibly responsible for conferring resistance to forage palm species on carmine cochineal quercetin-3-O-2', $6^{\prime}-$ dirhamnosylglucoside, quercetin rhamnosyl dihexoside, and isorhamnetin-3-sophoroside-7-rhamnoside

This work provided knowledge of the metabolic basis of no susceptibility in forage palm, which until then was not known, allowing future research to explore and establish a relationship between chemical composition and resistance of the host to the insect-plague.

In summary, this study allows determining the knowledge of the metabolic base of the studied species. Besides, it was possible to establish a relationship between species' biomarkers not susceptible to cochineal carmine.

\section{Acknowledgments}

This study was financed in part by the Coordenação de Aperfeiçoamento de Pessoal de Nível Superior (CAPES, Brasil), Finance Code 001.

The authors gratefully acknowledge financial support from the CNPq, National Council for Scientific and Technological Development (303791/2016-0), INCT BioNat, National Institute of Science and Technology (grant No. 465637/2014-0). We would also like to thank Embrapa (SEG 465637/2014-0).

\section{Author Contributions}

Thiago K. B. Matos was responsible for conceptualization, data curation, investigation and writing original draft; Jhonyson A. C. Guedes for conceptualization, data curation, investigation, software, validation, visualization, writing original draft, writing-review and editing; Elenilson G. Alves Filho for software, validation and writing original draft; Licia R. Luz for validation, visualization and writing original draft; Gisele S. Lopes for conceptualization, resources, validation, visualization, writing-review and editing; Ronaldo F. Nascimento for conceptualization, visualization, writing-review and editing; João A. Sousa for conceptualization, data curation, investigation and resources; Kirley M. Canuto for conceptualization, validation, visualization, writing-review and editing; Edy S. Brito for conceptualization, formal analysis funding acquisition, validation, visualization, writing-review and editing; Nivia S. Dias-Pini for conceptualization, validation, visualization, writing original draft, writing-review and editing; Guilherme J. Zocolo for conceptualization, formal analysis funding acquisition, investigation, project administration, resources, validation, visualization, writing original draft, writing-review and editing. 


\section{References}

1. Han, H.; Felker, P.; J. Arid Environ. 1997, 36, 133.

2. Aguirre, J. J.; de La Garza, H. T.; Xugasti, A. C.; Belmares, R. C.; Aguilar, N. C.; Asian Pac. J. Trop. Biomed. 2013, 3, 436.

3. Bezerra, B. G.; Araújo, J. S.; Pereira, D. D.; Laurentino, G. Q.; Silva, L. L.; Rev. Bras. Eng. Agric. Ambient. 2014, 18, 755.

4. Reyes-Aguero, J. A.; Aguirre, R. J. R.; Valiente-Banuet, A.; J. Arid Environ. 2006, 64, 549.

5. Cai, W.; Gu, X.; Tang, J.; Czech J. Food Sci. 2010, 28, 108.

6. Yahia, E. M.; Mondragon-Jacobo, C.; Food Res. Int. 2011, 44, 2311.

7. Bayar, N.; Kriaa, M.; Kammoun, R.; Int. J. Biol. Macromol. 2016, 92, 441.

8. Pinheiro, K. M.; da Silva, T. G. F.; Carvalho, H. F. S.; Santos, J. E. O.; de Morais, J. E. F.; Zolnier, S.; dos Santos, D. C.; Pesq. Agropec. Bras. 2014, 49, 939.

9. Ginestra, G.; Parker, M. L.; Bennett, R. N.; Robertson, J.; Mandalari, G.; Narbad, A.; Lo Curto, R. B.; Bisignano, G.; Faulds, C. B.; Waldron, K. W.; J. Agric. Food Chem. 2009, 57, 10323.

10. Stintzing, F. C.; Carle, R.; Mol. Nutr. Food Res. 2005, 49, 175.

11. Al-shahib, W.; Marshall, R. J.; Int. J. Food Sci. Nutr. 2003, 54, 247.

12. Ribeiro, E. M. O.; da Silva, N. H.; de Lima Filho, J. L.; de Brito, J. Z.; da Silva, M. P. C.; Cienc. Tecnol. Aliment. 2010, 30, 933.

13. Lee, E. H.; Kim, H. J.; Song, Y. S.; Jin, C.; Lee, K.-T.; Cho, J.; Lee, Y. S.; Arch. Pharm. Res. 2003, 26, 1018.

14. Santos-Zea, L.; Gutiérrez-Uribe, J. A.; Serna-Saldivar, S. O.; J. Agric. Food Chem. 2011, 59, 7054.

15. Feugang, J. M.; Konarski, P.; Zou, D.; Stintzing, F. C.; Zou, C.; Front. Biosci. 2006, 11, 2574.

16. Ventura-Aguilar, R. I.; Bosquez-Molina, E.; Bautista-Baños, S.; Rivera-Cabrera, F.; J. Sci. Food Agric. 2017, 97, 5065.

17. Flores-Hernández, A.; Murillo-Amador, B.; Rueda-Puente, E. O.; Salazar-Torres, J. C.; García-Hernández, J. L.; Troyo-Diéguez, E.; Rev. Mex. Biodivers. 2006, 77, 97.

18. Lopes, E. B.; Palma Forrageira: Cultivo, Uso Atual e Perspectivas de Utilização no Semi-árido Nordestino, $1^{\text {st }}$ ed.; EMEPA/FAEPA: João Pessoa, Brazil, 2007.

19. dos Santos, D. C.; Farias, I.; Lira, M. A.; dos Santos, M. V. F.; de Arruda, G. P.; Coelho, R. S. B.; Dias, F. M.; de Melo, J. N.; Manejo e Utilização da Palma Forrageira (Opuntia e Nopalea) em Pernambuco; Empresa Pernambucana de Pesquisa Agropecuária (Instituto Agronômico de Pernambuco): Recife, Brazil, 2006.

20. Smith, C. M.; Clement, S. L.; Annu. Rev. Entomol. 2012, 57, 309.

21. de Vasconcelos, A. G. V.; Lira, M. A.; Cavalcanti, V. L. B.; dos Santos, M. V. F.; Willadino, L.; Rev. Bras. Zootec. 2009, $38,827$.

22. Borges, L. R.; Santos, D. C.; Cavalcanti, V. A. L. B.; Gomes, E. W. F.; Falcão, H. M.; da Silva, D. M. P.; Acta Hortic. 2013, 359.

23. Mao, Q.; Bai, M.; Xu, J.; Kong, M.; Zhu, L.; Zhu, H.; Wang, Q.; Li, S.; J. Pharm. Biomed. Anal. 2014, 97, 129.

24. Fukusaki, E.; Kobayashi, A.; J. Biosci. Bioeng. 2005, 100, 347.

25. Sumner, L. W.; Mendes, P.; Dixon, R. A.; Phytochemistry 2003, 62, 817.

26. Krastanov, A.; Biotechnol. Biotechnol. Equip. 2010, 24, 1537.

27. Nyamundanda, G.; Brennan, L.; Gormley, I.; BMC Bioinf. 2010, 11,571 .

28. Worley, B.; Powers, R.; Curr. Metabolomics 2013, 1, 92.

29. Bouslimani, A.; Sanchez, L. M.; Gargb, N.; Dorrestein, P. C.; Nat. Prod. Rep. 2014, 31, 718.

30. Kind, T.; Fiehn, O.; BMC Bioinf. 2007, 8, 105.

31. Kind, T.; Fiehn, O.; Bioanal. Rev. 2010, 2, 23.

32. Moco, S.; Bino, R. J.; De Vos, R. C. H.; Vervoort, J.; TrAC, Trends Anal. Chem. 2007, 26, 855.

33. Yuliana, N. D.; Jahangir, M.; Verpoorte, R.; Choi, Y. H.; Phytochem. Rev. 2013, 12, 293.

34. GENE-E, https://software.broadinstitute.org/GENE-E/index. html, accessed in April 2021.

35. Matlab ${ }^{\mathrm{TM}}$ with the PLS Toolbox package, version R2020a; Eigenvector Research Inc., Wenatchee, WA, USA, 2020.

36. MarkerLynx XS, version 4.1 SCN719; Waters Corporation, Milford, USA, 2009.

37. ChemSpider: Search and share Chemistry, http://www. chemspider.com/, accessed in April 2021.

38. PubChem, https://pubchem.ncbi.nlm.nih.gov/, accessed in April 2021.

39. Nsuala, B. N.; Kamatou, G. P.; Sandasi, M.; Enslin, G.; Viljoen, A.; Biochem. Syst. Ecol. 2017, 70, 155.

40. Wrona, M.; Pezo, D.; Canellas, E.; Nerín, C.; J. Chromatogr. A 2016, 1432, 73.

41. Semedo, A. C. J.; Compostos Bioativos de Opuntia ficus indica; Universidade de Lisboa: Lisboa, 2012.

42. Abu-Reidah, I. M.; Ali-shtayeh, M. S.; Jamous, R. M.; Arráez-Román, D.; Segura-carretero, A.; Food Chem. 2015, $166,179$.

43. Aquino, R.; Behar, I.; D'agostino, M.; De. Simone, F.; Schettino, O.; Pizza, C.; Biochem. Syst. Ecol. 1987, 15, 667.

44. Saleem, M.; Kim, H. J.; Han, C. K.; Jin, C.; Lee, Y. S.; Phytochemistry 2006, 67, 1390.

45. Goupy, P.; Vian, M. A.; Chemat, F.; Caris-Veyrat, C.; Ind. Crops Prod. 2013, 44, 496.

46. Astello-García, M. G.; Cervantes, I.; Nair, V.; Santos-Díaz, M. S.; Reyes-Agüero, A.; Guéraud, F.; Negre-Salvayre, A.; Rossignol, M.; Cisneros-Zevallos, L.; Barba de la Rosa, A. P.; J. Food Compos. Anal. 2015, 43, 119. 
47. Guo, L.; Dou, L.-L.; Duan, L.; Liu, K.; Bi, Z.-M.; Li, P.; Liu, E.-H.; Chin. J. Nat. Med. 2015, 13, 711.

48. Farag, M. A.; Mohsen, M.; Heinke, R.; Wessjohann, L. A.; Food Res. Int. 2014, 64, 218.

49. Mata, A.; Ferreira, J. P.; Semedo, C.; Serra, T.; Duarte, C. M. M.; Bronze, M. R.; Food Chem. 2016, 210, 558.

50. Ferreres, F.; Taveira, M.; Pereira, D. M.; Valentão, P.; Andrade, P. B.; J. Agric. Food Chem. 2010, 58, 2854.

51. Brito, A.; Ramirez, J. E.; Areche, C.; Sepúlveda, B.; Simirgiotis, M. J.; Molecules 2014, 19, 17400.

52. Schmidt, S.; Zietz, M.; Schreiner, M.; Rohn, S.; Kroh, L. W.; Krumbein, A.; Rapid Commun. Mass Spectrom. 2010, 24, 2009.

53. Son, J.; Lee, B. H.; Nam, T. G.; Im, S.; Chung, D. K.; Lee, J. M.; Chun, O. K.; Kim, D.-O.; J. Food Biochem. 2014, 38, 518.

54. Guedes, J. A. C.; Santiago, Y. G.; dos Reis Luz, L.; Silva, M. F. S.; Ramires, C. M. C.; de Lima, M. A. C.; de Oliveira, V. R.; do Ó Pessoa, C.; Canuto, K. M.; de Brito, E. S.; Lima, M. F.; Alves, R. E.; Zampieri, D.; do Nascimento, R. F.; Zocolo, G. J.; Phytochem. Lett. 2020, 40, 26.

55. Cornell, H. V.; Hawkins, B. A.; Am. Nat. 2003, 161, 507.

56. Ferreyra, M. L. F.; Rius, S. P.; Casati, P.; Front. Plant Sci. 2012, 3,1 .

57. War, A. R.; Paulraj, M. G.; Ahmad, T.; Buhroo, A. A.; Hussain, B.; Ignacimuthu, S.; Sharma, H. C.; Plant Signal. Behav. 2012, 7, 1306.

58. Treutter, D.; Environ. Chem. Lett. 2006, 4, 147.

59. Hoffmann-Campo, C. B.; Harborne, J. B.; McCaffery, A. R.; Entomol. Exp. Appl. 2001, 98, 181.
60. Harborne, J. B.; Grayer, R.; The Flavonoids, Advances in Research Since 1986: Flavonoids and Insects; Chapman and Hall: London, 1994.

61. Green, P. W. C.; Stevenson, P. C.; Simmonds, M. S. J.; Sharma, H. C.; J. Chem. Ecol. 2003, 29, 811.

62. Simmonds, M. S. J.; Phytochemistry 2003, 64, 21.

63. Iwashina, T.; Biol. Sci. Space 2003, 17, 24.

64. Renwick, J. A. A.; Zhang, W.; Haribal, M.; Attygalle, A. B.; Lopez, K. D.; J. Chem. Ecol. 2001, 27, 1575.

65. Hoffmann-Campo, C. B.; Ramos Neto, J. A.; de Oliveira, M. C. N.; Oliveira, L. J.; Pesq. Agropec. Bras. 2006, 41, 1453.

66. Johnson, E. T.; Berhow, M. A.; Dowd, P. F.; J. Agric. Food Chem. 2007, 55, 2998.

67. Onyilagha, J. C.; Lazorko, J.; Gruber, M. Y.; Soroka, J. J.; Erlandson, M. A.; J. Chem. Ecol. 2004, 30, 109.

68. Jadhav, D. R.; Mallikarjuna, N.; Rathore, A.; Pokle, D.; Asian J. Agric. Sci. 2012, 4, 298.

69. Silva, T. R. F. B.; Almeida, A. C. D. S.; Moura, T. D. L.; da Silva, A. R.; Freitas, S. D. S.; Jesus, F. G.; Acta Sci. Agron. 2016, 38, 165.

70. Vieira, S. S.; Lourenção, A. L.; da Graça, J. P.; Janegitz, T.; Salvador, M. C.; de Oliveira, M. C. N.; Hoffmann-Campo, C. B.; Arthropod-Plant Interact. 2016, 10, 525.

71. Goławska, S.; Sprawka, I.; Łukasik, I.; Goławski, A.; J. Pest Sci. 2014, 87, 173.

Submitted: December 29, 2020

Published online: April 26, 2021 